\title{
Selective Solar Surface Solar Based on Black Chromium: Influence of Electrodeposition Parameters in the Absorption of Surfaces
}

\author{
Ithyara Dheylle Machado Medeiros ${ }^{a}$, Kelly Cristiane Gomes ${ }^{a, b} *$, \\ Ronny Peterson da Nobrega Gonçalves ${ }^{a}$, Gabriela Oliveira Galvão ${ }^{b}$ \\ aPrograma de Pós-Graduação em Engenharia Mecânica, Universidade Federal da Paraíba - UFPB, \\ João Pessoa, PB, Brasil \\ ${ }^{b}$ Departamento de Engenharia de Energias Renováveis, Universidade Federal da Paraíba - UFPB, \\ João Pessoa, PB, Brasil
}

Received: September 19, 2018; Revised: November 26, 2018; Accepted: January 07, 2019

The search for the reduction of costs for the implementation of renewable energies implies in the optimization of the parameters of the manufacturing processes of consolidated technologies. Among these technologies are the solar collectors composed of absorber films characterized by high absorption in the spectrum range corresponding to solar radiation and low emittance in the infrared range, allowing an increase in the collector's operating temperature $\left(300\right.$ to $\left.700^{\circ} \mathrm{C}\right)$. The present work produced selective surfaces based on black chrome absorber films on stainless steel substrate by electrodeposition. The substrates were immersed in a chromium trioxide bath with hexafluorosilicic acid using a $\mathrm{Pb}-\mathrm{Sn}$ electrode. In the project some parameters of deposition were evaluated (time, distance and voltage) and their influence on the surface roughness of the coatings obtained by correlating them with the absorptions of the produced surfaces. For this, the surfaces produced were characterized by UV-VisNIR, profilometry and SEM. The results indicate that the working distance directly influenced the increase of the films absorption and that the influence of the surface roughness on the film absorption is related to the electrodeposition time as the voltage is raised.

Keywords: selective surfaces, black chromium, electrodeposition, solar energy.

\section{Introduction}

The study of renewable sources of energy has become extremely relevant ahead of the growing world demand for energy ${ }^{1}$. Among these sources, solar energy stands out. One of its forms of exploitation is through the use of solar collectors, which promote the conversion of solar energy into thermal energy ${ }^{2}$. This conversion might have its efficiency amplified by the use of special coatings, called selective surfaces, which absorb the maximum possible radiation in the ultraviolet, visible and near infrared (UV-Vis-NIR) range of the electromagnetic spectrum ${ }^{3}$, while emitting little in the medium and distant infrared region, that is, they have an absorptance above $85 \%$ and emittance below $15 \%$ in the wavelength ranges mentioned ${ }^{4}$.

In addition to these optical characteristics, it is necessary that the coating does not suffer significant degradations during the lifetime of the collector. As a result, the selection of the most suitable deposition technique is fundamental for a good system performance. However, there are several techniques for obtaining selective solar coatings, such as: Electrodeposition, Chemical Vapor Deposition, Sputtering, Chemical Oxidation and Sol-Gel ${ }^{5}$.

Among these, the electrodeposition technique excels for its simplicity, low cost and possibility of large-scale production ${ }^{3}$, apart from making films with great hardness and mechanical resistance in addition to excellent optical and thermal proprieties ${ }^{6}$. Regarding the type of material, black chromium is one of the most used coatings for the efficient conversion of solar energy into thermal energy, that along with the electrodeposition technique compose the set of fundamental characteristics for high performance?

To assemble a reproducible electrochemical process of a black chromium, adhesive and homogeneous film on a metallic substrate with well defined optical and mechanical properties it is necessary to control all the electrochemical parameters involved and to understand their influence ${ }^{7}$. Therefore, the objective of the present study is to determine the set of parameters (voltage, anode-cathode distance and time) that produce selective black coatings electrodeposited on stainless steel substrates with the highest level of absorption in the UV-Vis-NIR region, and to correlate this maximum absorption with the thickness and the roughness of the obtained film.

The absorptance in thin films is the ratio of the amount of radiation absorbed by a solid to the amount of radiation incident on that solid. Therefore, when it is intended to evaluate the absorptance in the radiation range comprising the solar spectrum, it is necessary to verify how much of 
this radiation is absorbed by the solid. This parameter can be calculated from Equation $1^{8}$, shown below.

$$
\alpha=\frac{\int_{300}^{2500} \alpha_{\lambda} I_{\text {sun }} d \lambda}{\int_{300}^{2500} I_{\text {sun }} d \lambda}
$$

Where $\alpha_{\lambda}$ is the spectral absorptance of the solid, $\mathrm{I}_{\text {sun }}$ is the spectral distribution of the solar irradiation and $\alpha$ is the total hemispherical absorptance.

Considering the solid to be opaque, so, there is no radiation transmitted through it, the following equation is obtained:

$$
\alpha=\frac{\int_{300}^{2500}\left(1-\rho_{\lambda}\right) I_{\text {sun }} d \lambda}{\int_{300}^{2500} I_{\text {sun }} d \lambda}
$$

Where $\rho_{\lambda}$ is the spectral reflectance of the solid.

It is therefore observed from Equation 2 that the absorptance of opaque solid materials can be calculated by measuring its spectral reflectance, which can be done from appropriate analytical techniques, such as UV-Vis-NIR spectrophotometry.

\section{Experimental Techniques}

\subsection{Substrate cleaning}

The black chrome coatings were electrodeposited on AISI 304 stainless steel substrates with dimensions of $20 \mathrm{~mm} \times 30 \mathrm{~mm} \times 3 \mathrm{~mm}$. Before electrodeposition, the substrates were cleaned in order to eliminate any impurities that would influence the results and to allow a good adhesion between the film and the substrate ${ }^{9}$. They were initially submitted to a degreasing bath. Then, a solution of $0.768 \mathrm{~g} / \mathrm{ml}$ of citric acid was prepared, which was diluted for $5 \mathrm{~min}$ at $50{ }^{\circ} \mathrm{C}$. The substrates were then immersed in this heated solution, where they remained for $30 \mathrm{~min}$. After that time, the samples were removed from the solution and placed in a beaker with isopropyl alcohol, where they were submitted through an ultrasonic bath for $15 \mathrm{~min}$, being subsequently washed in distilled water, dried and stored.

\subsection{Electrolytic bath}

The black chromium electrodeposition of the present study used a bath composed of $274 \mathrm{~g} / 1$ of chromium trioxide $\left(\mathrm{CrO}_{3}\right)$ and $0.854 \mathrm{~g} / \mathrm{l}$ of hexafluorosilicic acid $\left(\mathrm{H}_{2} \mathrm{SiF}_{6}\right)$. The temperature of the bath varied from 24 to $30^{\circ} \mathrm{C}$ and the electric current density was in the range of 11 to $54 \mathrm{~A} / \mathrm{dm}^{2}$. These measurements are due to the applied voltage and the components of the electrochemical bath. However, the determined values are consistent with the literature. Daryabegy and Mahmoodpoor ${ }^{10}$, for example, worked with the temperature ranging from 26 to $35^{\circ} \mathrm{C}$ and current density of $19 \mathrm{~A} / \mathrm{dm}^{2}$ using the same components as the bath under analysis.

The variation of temperature and electric current density occurred due to the fact that the voltage source used only allowed the adjustment of the voltage, while the current oscillated as a function of this voltage. The source used was the continuous current one from the brand Agilent, model E3631A. For the electrodeposition, the substrate was connected to the negative pole (cathode) of the power supply, while a $\mathrm{Pb}-\mathrm{Sb}$ alloy (95-5\%) was connected to the positive pole (anode).

\subsection{Electrodeposition parameters}

During the electrodeposition process, some parameters may affect the morphology and the performance of the obtained film ${ }^{2}$. Moise et al. ${ }^{11}$, for example, cite the chemical composition of the bath, the current density and the temperature at which the electrodeposition occurs as parameters to be taken into account to obtain a reproducible coating.

While Window et al. ${ }^{12}$ emphasized the interference of time, performing electrodepositions between 20 and 80 seconds. Sheu et al. ${ }^{9}$ preferred to evaluate the behavior of the film as a function of the current density variation from 10 to $70 \mathrm{~A} / \mathrm{dm}^{2}$. In contrast, Spitz et al. ${ }^{13}$ adopted the anodecathode distance variation as one of their electrodeposition variables. From the above, it can be seen that many are the parameters studied in the literature.

As a result, the present study chose to vary three parameters of electrodeposition (voltage, anode-cathode distance and time), since these are the ones that present greater possibilities of modifications allowing a greater range of study. So that eight samples were obtained, so that three specimens were produced for each set of parameters, totaling the production of 24 samples, according to Table 1.

The choices of voltage values ( 5 and $6 \mathrm{~V}$ ), anode-cathode distance (5 and $10 \mathrm{~cm}$ ) and time (5 and $10 \mathrm{~min}$ ) were based on literature studies. According to Daryabegy and Mahmoodpoor ${ }^{10}$ the appropriate time for electrodeposition of black chromium is 0.5 to 5 minutes. In terms of anodecathode distance, Spitz et al ${ }^{13}$ used 4 and $7 \mathrm{~cm}$, while Lee $^{6}$ adopted $5 \mathrm{~cm}$. Through these works, the time and the distance

Table 1. Samples obtained with the variation of the parameters.

\begin{tabular}{cccc}
\hline \multirow{2}{*}{$\begin{array}{c}\text { Sample } \\
\text { Number }\end{array}$} & \multicolumn{3}{c}{ Electrodeposition Parameter } \\
\cline { 2 - 4 } & Voltage (V) & Distance (cm) & Time (min) \\
\hline 1 & 5 & 10 & 10 \\
2 & 5 & 10 & 5 \\
3 & 6 & 10 & 10 \\
4 & 6 & 10 & 5 \\
5 & 5 & 5 & 10 \\
6 & 5 & 5 & 5 \\
7 & 6 & 5 & 10 \\
8 & 6 & 5 & 5 \\
\hline
\end{tabular}


of $5 \mathrm{~min}$ and $5 \mathrm{~cm}$, respectively, were chosen. While $10 \mathrm{~min}$ and $10 \mathrm{~cm}$ were used in order to investigate if larger times and distances would provide films with higher absorption.

Regarding the voltage, since the equipment used in the present study did not allow the study of the current density, the voltage was chosen to represent this parameter. So, through the works of Sheu et al. ${ }^{9}$ and Daryabegy and Mahmoodpoor ${ }^{10}$, a mean of tension was determined in which the best results of these works were obtained.

\subsection{Characterization of selective films}

The main parameter to be evaluated, regarding the optical properties of the selective films, is the ability of these materials to absorb solar radiation. For this purpose, the electrodeposited coatings were subjected to UV-Vis-NIR spectrophotometry. The equipment used was a Spectrophotometer in the region of UV-Vis-NIR, by Shimadzu, model UV-2600 operating in the region of the electromagnetic spectrum from $220 \mathrm{~nm}$ to $1400 \mathrm{~nm}$ with measurement of reflectance, using the integrating sphere accessory that allows the analysis of films.

This characterization was used to determine the reflectance of the coatings. Knowing that, according to Kirchhoff's law, the sum of the absorptance, transmittance and reflectance of a surface at a particular wavelength is equal to one ${ }^{14}$. This law can be written according to Equation 3 below:

$$
\alpha+\tau+\rho=1
$$

Where, $\alpha$ is the absorptance, $\tau$ is the transmittance and $\rho$ is the reflectance of the surface.

On opaque surfaces in which the transmittance is zero ${ }^{15}$, the equation takes the form below:

$$
\alpha+\rho=1 \rightarrow \alpha=1-\rho
$$

Thus, to obtain the levels of absorption of the coating produced in the present study, the Equation 4 described above was applied.

The determination of the surface roughness of the electrodeposited films as well as the measurement of the thickness of the surfaces obtained on the steel were identified by the CCI MP non-contact optical profilometer, by Taylor Hobson, connected to a computerized unit containing Talysurf CCI software (Taylor Hobson, United Kingdom) for obtaining and analyzing the data.

For the determination of surface roughness, 14 uniformly spaced readings were obtained along each of the samples. So the value of Ra provided in the results is the average of these readings.

The determination of film thickness was obtained using the "step" method, in which only part of the substrate undergoes deposition. This methodology can be better understood by observing Figure 1, in which it exhibits the substrate before and after the procedure.
After the electrodeposition, the transition region was subjected to profilometry and it was possible to determine the thickness of the film, as can be observed in Figure 2.

The visualization of the morphological characteristics of the coatings was obtained through the use of a Scanning Electron Microscope (SEM) applying the operation principle of secondary electrons with environmental module. The microscope used was the Quanta 450 model, by FEI.

\section{Results and Discussion}

\subsection{Spectrophotometry in the UV-Vis-NIR}

The absorptive films produced by electrodeposition of black chromium, through alternation of voltage, anodecathode distance and residence time in the electrolytic bath, were subjected to radiation with wavelengths in the range of $220 \mathrm{~nm}$ to $1400 \mathrm{~nm}$, in order to determine spectral reflectance of these films. After the proper conversions to levels of absorptance, Figure 3 shows the results obtained on the steel substrate.

Through Figure 3, it is noticeable that sample 6 presented the highest levels of absorption and of absorption stability throughout the spectrum under analysis $(220 \mathrm{~nm}$ to $1400 \mathrm{~nm}$ - with a mean of $94.60 \%$ ). When considering the standard deviation, sample 6 reached a maximum absorptance of $96 \%$. This means that, regarding the electrodeposition parameters, the $5 \mathrm{~V}$ and $5 \mathrm{~cm}$ distance between anode-cathode and the time of 5 minutes in the electrolytic bath allowed the best conditions in terms of absorption and stability.

The data shown in Figure 3 corroborate with the literature as observed in the work of Bayati et al. ${ }^{16}$ which determined that the electrodeposition time of 5 min provided and absorption around 91 to $96 \%$ in black chromium based absorber films. The smaller anode-cathode working distances are the ones that provide the best results, as was perceived by Spitz et al. ${ }^{13}$.

This can be explained by the fact that Newby ${ }^{17}$ states that an excellent method for obtaining a uniform deposition thickness is to make the anode-cathode distance the same at all points of a part, which is more likely at smaller distances. Associated with the fact that Mandich ${ }^{18}$ reported that the ability of an electrochemical bath to uniformly deposit metal on the surface of the cathode is a measure of its throwing power, the geometrical properties of the system being that is the shape and the distance from the anode to the cathode an factors influencing this power. Hence, the smaller the distance, the greater the deposition capacity of the bath, which possibly increases the absorption of the film.

\subsection{Optical perfilometry}

The results of the measurement of the roughness parameter $R a$ of the coatings obtained on the steel substrate can be seen in Table 2, as well as the thicknesses (maximum, minimum and average). 


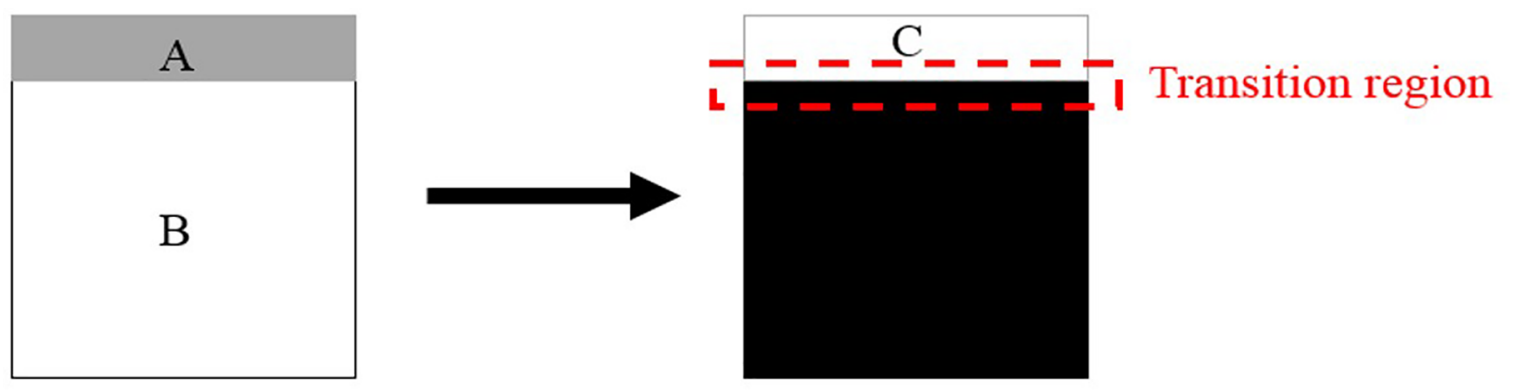

\section{Substrate before electroplating}

\section{Substrate after electroplating}

Figure 1. (a) region of the substrate that has been prevented from being deposited, (b) region of the substrate where the deposition will be made, (c) region of the substrate that was not covered during electrodeposition.

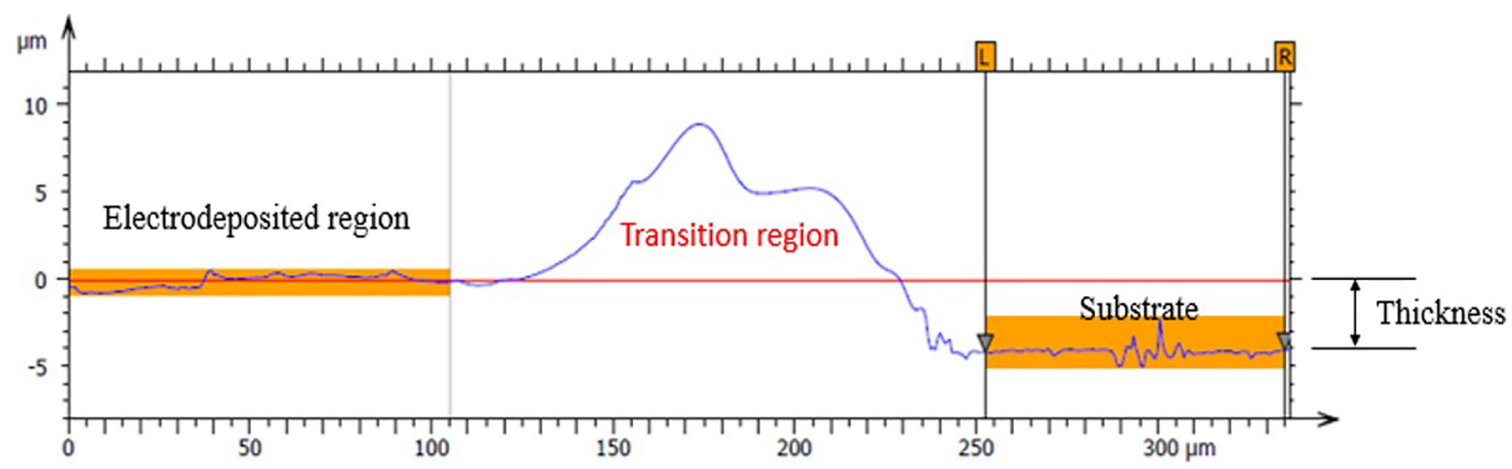

Figure 2. Determination of the thickness in the sample 6.

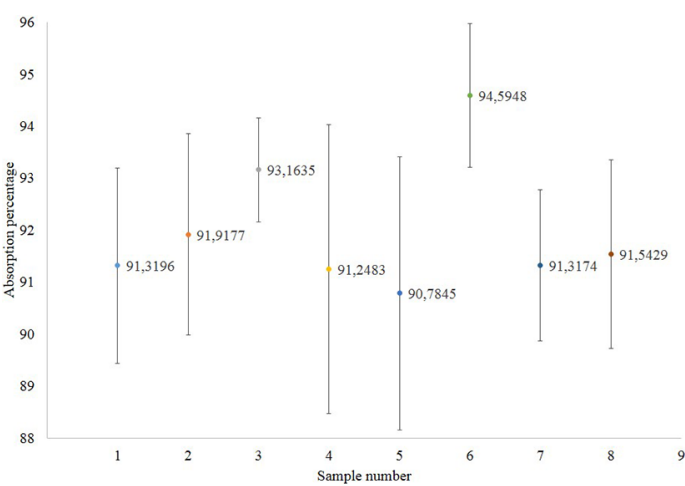

Figure 3. Average and standard deviation of the absorptance for the different absorber films deposited on steel substrates.

Table 2 shows an increase in roughness (parameter $\mathrm{Ra}$ ) as the voltage was increased. The same was evidenced by Sheu et al. ${ }^{9}$ when studying the effects of the current density of the electrodeposition of black chromium coatings. As for the time, it was determined that the longer the electrodeposition time the larger the surface roughness obtained (parameter $\mathrm{Ra}$ ). When establishing a relation with the absorptance, it was observed that the film that obtained the best response (sample 6) was also the one that presented the lowest level of roughness $(\mathrm{Ra}=0.05 \mu \mathrm{m}$ and average thickness of $3.63 \mu \mathrm{m})$.
Table 2. Parameter Ra of the electrodeposited films on the steel substrate and the film thicknesses.

\begin{tabular}{ccccc}
\hline $\begin{array}{c}\text { Sample } \\
\text { Number }\end{array}$ & $\operatorname{Ra}(\mu \mathrm{m})$ & $\begin{array}{c}\text { Maximum } \\
\text { thickness of } \\
\text { the film }(\mu \mathrm{m})\end{array}$ & $\begin{array}{c}\text { Minimum } \\
\text { thickness } \\
\text { of the } \\
\text { film }(\mu \mathrm{m})\end{array}$ & $\begin{array}{c}\text { Average } \\
\text { thickness } \\
\text { of the } \\
\text { film } \\
(\mu \mathrm{m})\end{array}$ \\
\hline 1 & 0.29 & 5.68 & 4.98 & 5.33 \\
2 & 0.09 & 7.00 & 5.44 & 6.22 \\
3 & 0.43 & 3.28 & 2.12 & 2.70 \\
4 & 0.26 & 3.13 & 2.03 & 2.58 \\
5 & 0.19 & 2.66 & 1.71 & 2.18 \\
6 & 0.05 & 3.88 & 3.38 & 3.63 \\
7 & 0.29 & 4.69 & 4.17 & 4.43 \\
8 & 0.33 & 5.05 & 4.39 & 4.72 \\
\hline
\end{tabular}

In relation to the working distance, the roughness is smaller at smaller distances due to the power of the bath, which at lower distances produces a greater uniformity of the film produced by the increase ${ }^{17,18}$.

\subsection{Scanning Electron Microscope (SEM)}

The SEM analysis allowed the visualization of the surfaces of the films, thus enabling the comprehension of 
the solidification processes of the films. Figure 4 shows the surfaces of the coatings.

The Figure 5 shows the surfaces of the coatings that obtained the lowest (sample 5) and highest (sample 6) absortance.

The micrography of the present study corroborate with the literature, as in the work of Aguilar et al. ${ }^{3}$ which produced thin films of white and black chromium by electrodeposition on steel substrates, so that from the SEM analysis, they verified that black chromium has a lamellar morphology that leads to a strong level of dispersion, indicating a higher roughness coefficient of this film and, therefore, the dark appearance. Surviliené et al. ${ }^{19}$ made black chromium films electrodeposited on steel substrates and realized through SEM that black chromium coatings have a micro-fissured structure with numerous lamellar crystals.
Protsenko et al. ${ }^{20}$ observed that when the thickness of the coatings is not very high $(\sim 10 \mu \mathrm{m})$, the surface contains a large number of spheroids with different diameters (up to several micrometers), which coincides with that observed in Figure 2, in which the films have thicknesses smaller than $10 \mu \mathrm{m}$ as shown in Table 2 .

Thus, through the visualization of Figure $5 \mathrm{~b}$, it can be seen that a more uniform surface with the micro-fissured region in prominence, allowed the obtainment of higher levels of absorption.

\section{Conclusion}

The solar selective coating made of black chromium by the electrodeposition technique that obtained the highest level of absorption, with a mean of $94.6 \%$ and maximum of $96 \%$
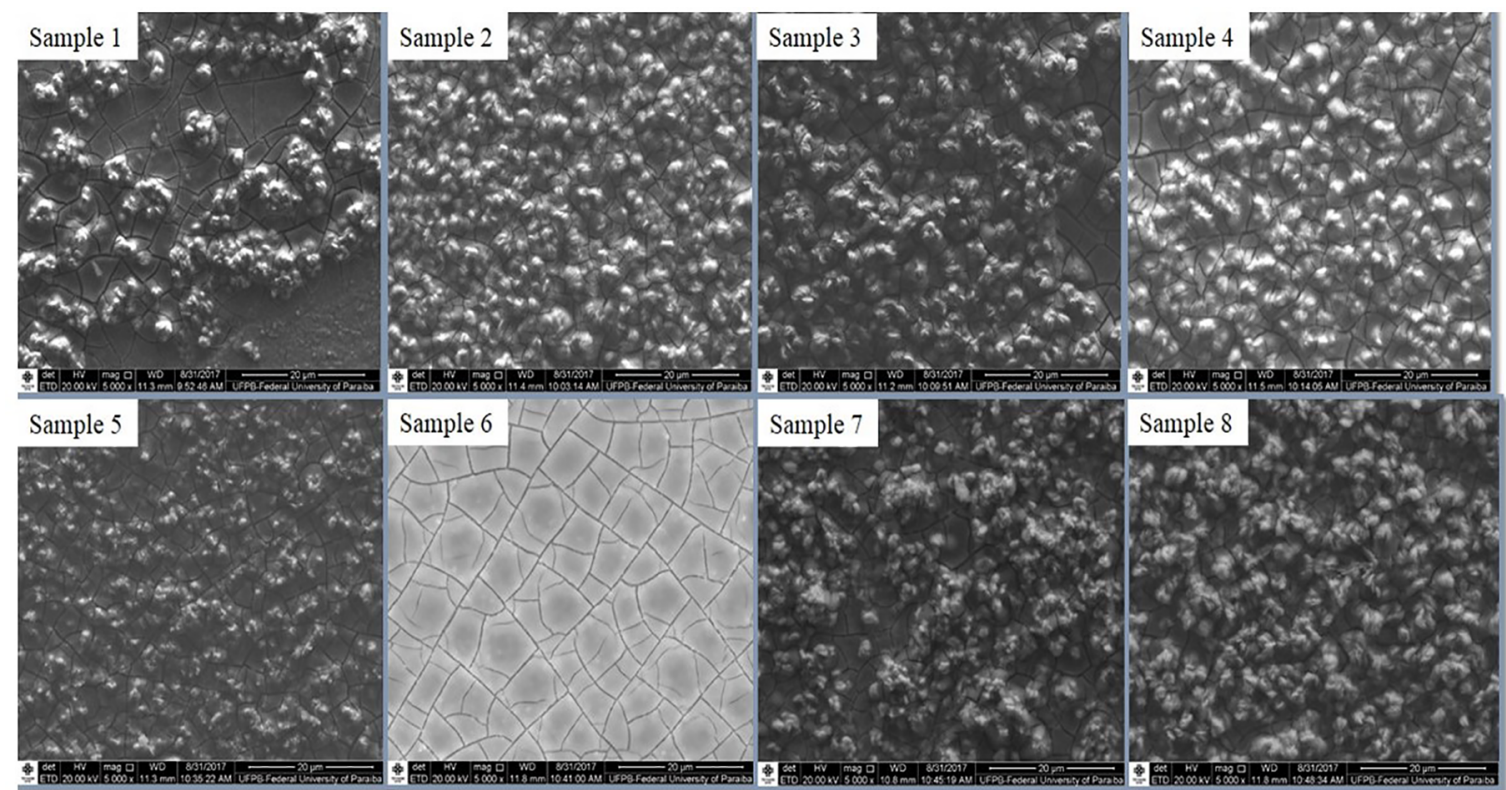

Figure 4. Micrography of films produced (Films 1 to 8).
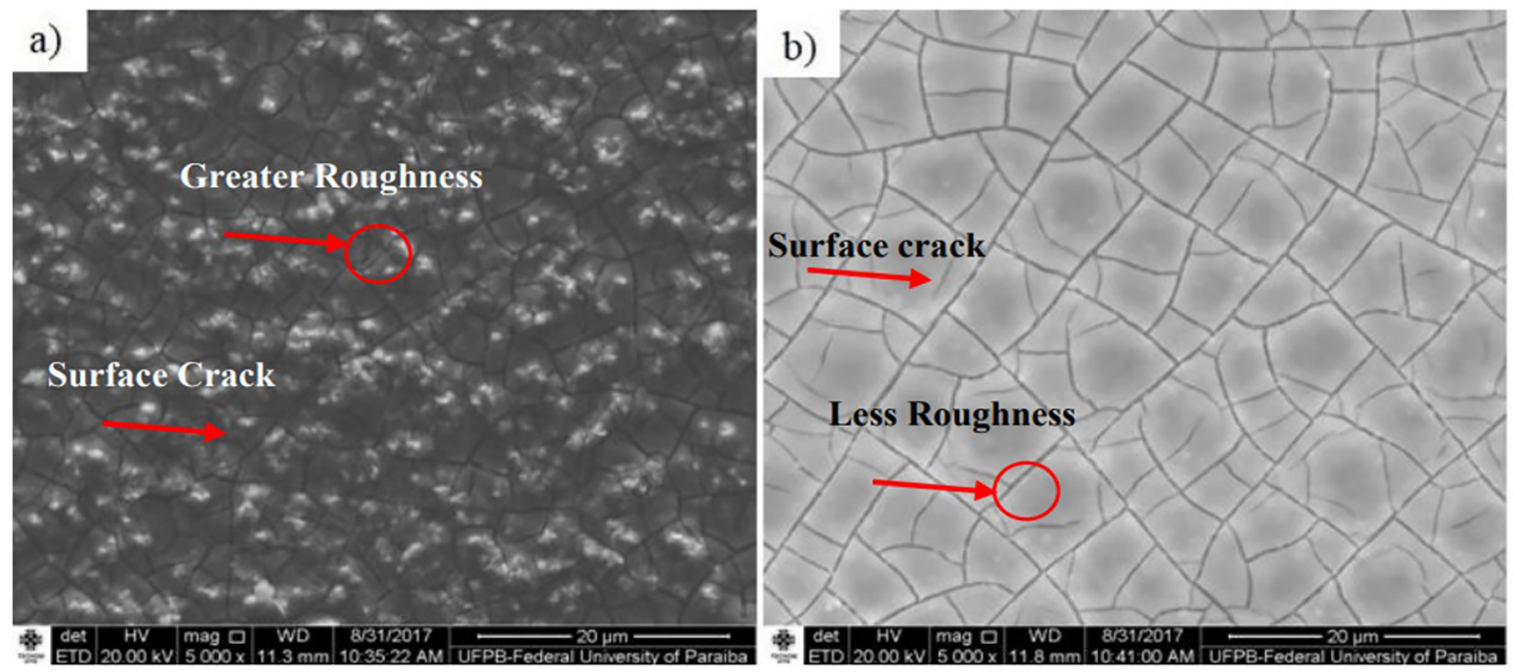

Figure 5. Micrography of (a) sample 5 and (b) sample 6. 
in the UV-Vis-NIR range was the one produced with the voltage of $5 \mathrm{~V}$, the distance of $5 \mathrm{~cm}$ between anode-cathode and the time of $5 \mathrm{~min}$ in the electrolytic bath.

This set of parameters allowed the formation of a low roughness surface $(\mathrm{Ra}=0.05 \mu \mathrm{m})$ when compared to the other films obtained, in addition to an average thickness of $3.63 \mu \mathrm{m}$.

This roughness was observed by SEM, in which it was determined that a greater uniformity allowed higher levels of absorption of the film under study.

\section{Acknowledgement}

Financial support for the present work was provided by the CAPES and CNPq. The authors wish to thank Rebeca Tibau and Isaque Porto of the Biomaterials and Rapid Solidification Laboratories of the UFPB to assist in the measurements of profilometry and microscopy, as well to the members of the Laboratory of Synthesis and Characterization of Thin Films by UV-Vis-NIR measurements.

\section{References}

1. de Medeiros IDM, da Silva Neto JF, Leite KS, da Silva AKB, Gomes KC. Eletrodeposição de filmes de cromo negro em substratos de cobre para absorção solar. Enciclopédia Biosfera. 2017;14(26):1370-1379.

2. Cao F, McEnaney K, Chen G, Ren Z. A review of cermet-based spectrally selective solar absorbers. Energy \& Environmental Science. 2014;7(5):1615-1627.

3. Aguilar M, Barrera E, Palomar-Pardavé M, Huerta L, Muhl S. Characterization of black and white chromium electrodeposition films: surface and optical properties. Journal of Non-Crystalline Solids. 2003;329(1-3):31-38.

4. Nunes RAX, Costa VC, Sade W, Araújo FR, Silva GM. Selective Surfaces of Black Chromium for Use in Solar Absorbers. Materials Research. 2018;21(1):e20170556.

5. Kennedy CE. Review of Mid-to High-Temperature Solar Selective Absorber Materials. Golden: National Renewable Energy Laboratory; 2002.

6. Lee DB. Oxidation of Cr-C electroplating between 400 and $900^{\circ} \mathrm{C}$ in air. Materials and Corrosion. 2008;59(7):598-601.
7. Jafari S, Rozati SM. Characterization of black chrome films prepared by electroplating technique. In: World Renewable Energy Congress 2011 - Sweden; 2011 May 8-13; Linköping; Sweden. Linköping University Electronic Press; 2011. p. 3999-4005.

8. Çengel YA, Ghajar AJ. Heat and Mass Transfer: Fundamentals and Applications. New Delhi: Tata McGraw-Hill; 2011.

9. Sheu HH, Lu CE, Lee HB, Pu NW, Wu PF, Hsieh SH, et al. Electrodeposition of black chromium-cobalt alloy based on trivalent sulfate electrolyte. Journal of the Taiwan Institute of Chemical Engineers. 2016;59:496-505.

10. Daryabegy M, Mahmoodpoor AR. Method of manufacturing absorbing layers on copper for solar applications (I). IESCO Journal of Science and Technology. 2006;2(1):35-39.

11. Moise V, Cloots R, RulmontA. Study of the electrochemical synthesis of selective black coatings absorbing solar energy. International Journal of Inorganic Materials. 2001;3(8):1323-1329.

12. Window B, Ritchie IT, Cathro K. Selective electroplated chromium blacks. Applied Optics. 1978;17(16):2637-2644.

13. Spitz J, Van Danh T, Aubert A. Chromium black coatings for photothermal conversion of solar energy, part I: Preparation and structural characterization. Solar Energy Materials. 1978;1(34):189-200.

14. Sukhatme SP. Solar Energy - Principles of Thermal Collection and Storage. New Delhi: Tata McGraw-Hill; 2001.

15. Kreider JF, Kreih F. Solar Energy Handbook. New York: McGrawHill; 1981.

16. Bayati MR, Shariat MH, Janghorban K. Design of chemical composition and optimum working conditions for trivalent black chromium electroplating bath used for solar thermal collectors. Renewable Energy. 2005;30(14):2163-2178.

17. Newby KR. Functional chromium plating. Metal Finishing. 2000;98(1):223-224, 226, 228, 230-233.

18. Mandich NV. Chemistry \& Theory of Chromium Deposition: Part 1--Chemistry. Plating \& Surface Finishing. 1997;84(5):108-115.

19. Survilienẻ $S$, Češūnienė A, Juškènas R, Selskienė A, Bučinskienė D, Kalinauskas P, et al. The use of trivalent chromium bath to obtain a solar selective black chromium coating.Applied Surface Science. 2014;305:492-497.

20. Protsenko VS, Danilov FI, Gordiienko VO, Kwon SC, Kim M, Lee JY. Electrodeposition of hard nanocrystalline chrome from aqueous sulfate trivalent chromium bath.Thin Solid Films. 2011;520(1):380-383. 